\title{
Phyco-Mediated Synthesis of Ag/AgCl Nanoparticles Using Ethanol Extract of a Marine Green Algae, Ulva Fasciata Delile with Biological Activity
}

\author{
Hamed Esmaeil Lashgarian 1(D), Maryam Karkhane 1(D), Alaa Kamil Alhameedawi ${ }^{\text {(DD }}$, Abdolrazagh \\ Marzban 3,*iD
}

1 Department of Medical Biotechnology, Faculty of Medicine, Lorestan University of Medical Sciences, Khorramabad, Iran; hamedesmaiili@gmail.com (H.E.L.); Maryam_karkhane@hotmail.com (M.K.);

2 Iraqi Ministry of Education, Baghdad, Iraq; Alaa.alkamily@gmail.com (A.K.A.);

3 Razi Herbal Medicines Research Center, Lorestan University of Medical Sciences, Khorramabad, Iran; marzban86@gmail.com (A.M.);

* Correspondence: marzban86@gmail.com;

Scopus Author ID 55860483200

Received: 11.02.2021; Revised: 5.03.2021; Accepted: 9.03.2021; Published: 23.03.2021

\begin{abstract}
Due to nanotechnology's unique capabilities in the fields of medicine, a great deal of attention has recently been devoted to the development of nanoparticle-based different drugs. In this study, silver/silver chloride nanoparticles (Ag/AgCl-NPs) were synthesized by an ethanol extract of Ulva fasciata (UF-extract) to examine their biological properties. The formation of $\mathrm{Ag} / \mathrm{AgCl}-\mathrm{NPs}$ was verified by changing the color solution and detecting a prominent peak of the Uv-visible spectrum. SEM, TEM, XRD, FTIR, DLS, and Zeta potential were applied to the analysis of physicochemical properties of NPs. After that, NPs were studied to determine their antifungal, antioxidant, and anticancer activities. SEM and TEM micrographs have shown that $\mathrm{Ag} / \mathrm{AgCl}-\mathrm{NPs}$ have appropriate nanostructures below $100 \mathrm{~nm}$ with spherical shapes. The XRD pattern of Ag/AgCl-NPs demonstrated irregular crystalline phases suggesting an amorphous structure. The FTIR spectrum verified the role of functional groups of algal metabolites in NPs synthesis and stabilization. The Zeta potential predicted a surface charge of about- $16 \mathrm{mV}$. The results of antifungal experiments showed that $\mathrm{Ag} / \mathrm{AgCl}-\mathrm{NPs}$ have high inhibitory activity against Candida albicans and C. Glabrata. The antioxidant activity of Ag/AgClNPs confirmed their strong antioxidant capacity. Finally, the anti-cancer activity of Ag/AgCl-NPs was calculated based on $\mathrm{LD}_{50}$ to be approximately $20 \mu \mathrm{g}$, which was almost twice as potent as the anticancer effect of the UF-extract. Taken together, phyco-fabricated Ag/AgCl-NPs seem to be biocompatible, cost-effective, and easy-to-use materials that can be used to achieve high potent drugs against various diseases, including pathogens and cancer cells.
\end{abstract}

Keywords: Ag/AgCl-NPs; Ulva fasciata; antifungal activity; antioxidant activity; anti-cancer activity.

(C) 2021 by the authors. This article is an open-access article distributed under the terms and conditions of the Creative Commons Attribution (CC BY) license (https://creativecommons.org/licenses/by/4.0/).

\section{Introduction}

Nowadays, nanotechnology has gained wide uses in a wide variety of fields. By integrating nanostructures into various industries, including electronics, building, medical and agricultural products, their performance has improved [1]. However, the processing of nanoproducts for the production of high-quality products has also been associated with challenges $[2,3]$. Since most NPs are synthesized based on chemical and physical processes, chemical 
residues can affect the final products' quality. On the other hand, toxic by-products and solvents in NPs synthesis limit their use for medicinal purposes [4]. Biocompatible and cost-effective methods based on the use of biomolecules and biological systems are being developed. In particular, the synthesis of NPs using green methods is an important strategy for overcoming the disadvantages of other methods [5]. Bioactive compounds, such as plant, bacterial, fungal, and algal metabolites, have a high propensity for synthesizing metal NPs as a reducing and capping agent [3].

Silver (Ag) has gained increasing attention among biologically synthesized NPs due to its high biocompatibility and ease of synthesis [6]. Biological agents such as polyphenols, terpenes, flavonoids, enzymes, proteins, carbohydrates, secondary fungal metabolites, and bacteria have been extensively used in the production of Ag-NPs. The biological activities of Ag-NPs, including antifungal, anti-parasitic, anti-cancer, anti-inflammatory, and antibacterial, have been documented in a variety of literature [7-9]. On the other hand, it has been mentioned that the biological function of Ag-NPs is affected by their synthesis methods [1]. Therefore, one of the effective factors in the bioproduction of NPs is the reducing power and capping capacity of biologically active metabolites of plant extracts or biomolecules [10]. Seaweeds are a potential source of biologically active compounds that could reduce and capping agent for metal NPs [11]. In this respect, Ag-NPs have been produced from seaweed metabolites with different biological functions [12, 13]. However, few studies have been reported on the synthesis of carcinogenic $\mathrm{Ag}-\mathrm{NPs}$, including silver chloride $(\mathrm{AgCl})$ from seaweed metabolites. In this study, an ethanol extract of Ulva fasciata was used to produce AgCl-NPs. After that, their biological activity, including antifungal, antioxidant, and anti-cancer activity, was examined.

\section{Materials and Methods}

\subsection{Materials and supplements.}

The marine green algae Ulva fasciata was collected from Chabahar, Oman Sea, southern coast of Iran. Silver nitrate $\left(\mathrm{AgNO}_{3}\right)$ was synthetic grade from Merck Company (Merck, Darmstadt, Germany). Fungal strains, C. albicans, and C. glabrata were provided from the microbial collection of IROST (Tehran, Iran). Fungal media were purchased from HiMedia Co. (Bombay, India). MTT (3-(4, 5-dimethylthiazol-2-yl)-2, 5-diphenyltetrazolium bromide) was procured from Sigma (USA). Other chemicals were high pure grade as-received. RPMI 1640 was from Gibco (Invitrogen Co. USA). The A549 cell line was provided from the Pasteur Institute cell collection (Tehran, Iran).

\subsection{Ethanol extract preparation.}

The extract solution was prepared by adding $10 \mathrm{~g}$ of dried biomass of $U$. fasciata to ethanol: deionized water (70:30). The sample solution was heated in a bath-sonicator at $75^{\circ} \mathrm{C}$ under a frequency of $42 \mathrm{kHz}$ for $90 \mathrm{~min}$. After that, the extract was passed through from Whatman filter paper. The filtrate was concentrated in a rotary evaporator and dried in an oven at $60{ }^{\circ} \mathrm{C}$ for $24 \mathrm{~h}$. The dried extract was stored at $4{ }^{\circ} \mathrm{C}$ for further studies. 


\subsection{Biofabrication of Ag/AgCl-NPs.}

To prepare the reaction solution, $100 \mathrm{mg}$ of dried extract was dissolved in $50 \mathrm{ml}$ deionized water. A volume of $50 \mathrm{ml}$ of silver nitrate $(1 \mathrm{mM})$ was mixed into the extract solution in a $250 \mathrm{ml}$ flask. The flask was stirred under room temperature for $12 \mathrm{~h}$, and a spectrophotometer monitored the formation of $\mathrm{Ag} / \mathrm{AgCl}-\mathrm{NPs}$ as the solution color changed. After completing the NPs formation, the mixture was centrifuged at 14,000 rpm for $15 \mathrm{~min}$, and the precipitated NPs were washed twice with deionized water. Finally, the obtained $\mathrm{Ag} / \mathrm{AgCl}-\mathrm{NPs}$ were dried in the oven at $65^{\circ} \mathrm{C}$ for $12 \mathrm{~h}$.

\subsection{Characterization of $\mathrm{Ag} / \mathrm{AgCl}-\mathrm{NPs}$.}

The physicochemical features of biosynthesized $\mathrm{Ag} / \mathrm{AgCl}-\mathrm{NPs}$ were studied by analytical methods, including Uv-visible spectrophotometry (Shimadzu apparatus, model: UV1650 PC, Japan); Fourier transformed infrared spectrum (FTIR) was measured by an Agilent Technologies FTIR instrument (Cary 630 FTIR spectrometer, Germany), The X-ray diffraction pattern (XRD) was constructed using an X-ray diffractometer system (XRD Bruker, model, D8-Advance, Germany); Field emission scanning electron microscopy (FE-SEM) and Energy Dispersive X-ray (EDX) were taken using an apparatus, MIRA3 TESCAN-XMU model (Czech Republic), Transmission electron microscopy (TEM) was conducted using a PhilipsEM208S system (Netherlands); particle size distribution (DLS) along with zeta potential was determined by a Zetasizer instrument (Malvern 3000, GB).

\subsection{Antifungal activity of $\mathrm{Ag} / \mathrm{AgCl}-\mathrm{NPs}$.}

\subsubsection{Well diffusion assay.}

Antifungal activity of synthesized $\mathrm{Ag} / \mathrm{AgCl}-\mathrm{NPs}$ was examined against Candida albicans (ATCC 10231), Candida glabrata (ATCC 90030). Agar well diffusion assay was used for the antifungal experiments on Muller Hinton Agar (MHA). After preparing MHA plates, fungal inoculums were spread over the surface of agar plates. Five wells with $6 \mathrm{~mm}$ diameter were punched into each MHA plate using a sterile cock borer. A volume of $20 \mu 1 \mathrm{of} \mathrm{Ag/AgCl-}$ NPs at different concentrations $(100,50,25,12.5,6.25,3.12$ and $0 \mu \mathrm{g} / \mathrm{ml})$ was added into each well. The agar plates were incubated at $25^{\circ} \mathrm{C}$ for $72 \mathrm{~h}$. The antifungal activity of the $\mathrm{Ag} / \mathrm{AgCl}-$ NPs was determined by measuring the diameter of the inhibition zone around the agar wells. Nystatin and phosphate buffer solution (PBS) were subjected as positive and negative controls, respectively.

\subsubsection{Macro-dilution assay.}

This method was applied to determine MIC and MFC of biosynthesized Ag/AgCl-NPs against fungal strains. For this, the highest concentration of $\mathrm{Ag} / \mathrm{AgCl}-\mathrm{NPs}$ was considered as a stock solution having $500 \mu \mathrm{g} / \mathrm{ml}$. Two-fold serial dilutions were obtained from primary stock, including 200, 100, 50, 25, 12.5, 6.25, 3.12 and $0.78 \mu \mathrm{g} / \mathrm{ml}$. The fungal strains were grown in the presence of each dilution in sterile glass tubes containing $5 \mathrm{ml}$ of Muller Hinton broth (MHB). After incubating at $25^{\circ} \mathrm{C}$ for $72 \mathrm{~h}$, those dilutions that showed at least $99 \%$ inhibition of fungal growth were considered MIC values. The MFC value also included the highest dilution in which no fungal growth was observed after $72 \mathrm{~h}$ on the MHA plate. 


\subsection{Antioxidant activity of $\mathrm{Ag} / \mathrm{AgCl}-\mathrm{NPs}$.}

The scavenging activity of the DPPH free-radical was studied previously. Briefly, $1 \mathrm{ml}$ of DPPH solution ( $0.1 \mathrm{mM}$ in absolute methanol) was added to $4 \mathrm{ml}$ of $\mathrm{Ag} / \mathrm{AgCl}-\mathrm{NPs}$ at different concentrations $(1.25-20 \mathrm{mg} / \mathrm{ml})$. The reaction mixture was agitated and incubated at room temperature for $15 \mathrm{~min}$ in darkness. The reduction of the DPPH radicals was measured by monitoring the absorption solution at $517 \mathrm{~nm}$ in regular time intervals. The lowest adsorption of the reaction mixture indicated higher antioxidant activity of the Ag/AgCl-NPs. BHT and L-ascorbic acid were applied as antioxidant standards for comparing with $\mathrm{Ag} / \mathrm{AgCl}-$ NPs. Equation 1 was used to determine the DPPH radical scavenging capacity as follows:

$$
\text { Scavenging effect }(\%)=\left[\left(\mathrm{A}_{0}-\mathrm{A}_{1}\right) / \mathrm{A}_{0}\right] \times 100
$$

\subsection{Cytotoxicity assay of $\mathrm{Ag} / \mathrm{AgCl}-\mathrm{NPs}$.}

The cytotoxic effect of Ag/AgCl-NPs was examined on the A549 cells. For this, $10^{5}$ cells were seeded in each well of a 96-well plate containing $100 \mu$ of RPMI medium supplemented with 10\% FBS, Streptomycin $(100 \mu \mathrm{g} / \mathrm{ml})$, and penicillin $(100 \mathrm{U} / \mathrm{ml})$. Various concentrations of $\mathrm{Ag} / \mathrm{AgCl}-\mathrm{NPs}(10-1000 \mu \mathrm{g} / \mathrm{ml})$ were treated in each well. After that, the plate was incubated at $37{ }^{\circ} \mathrm{C}$ under $5 \% \mathrm{CO}_{2}$ with $95 \%$ humidity for $24 \mathrm{~h}$. UF-extract was used as a comparative control. After $24 \mathrm{~h}$ incubation, $10 \mu \mathrm{l}$ of MTT reagent $(5 \mathrm{mg} / \mathrm{ml})$ was added to the wells, and the plate was incubated for $3 \mathrm{~h}$. After that, $100 \mu \mathrm{l}$ of DMSO was slowly pipetted to each well. Finally, the absorbance was recorded at $520 \mathrm{~nm}$ using an ELISA plate reader. The results were expressed as the percentage of survival relative to untreated cells (negative control). Also, the results were used to plot a dose-response curve and to determine $\mathrm{IC}_{50}$ value.

\subsection{Statistical analysis.}

All experiments were conducted in at least three replicates, and their results were used as mean \pm SD. GraphPad Prism (version 7.03, San Diego, CA) was used to calculate the results and graphs preparations. Statistical analysis was performed within the groups using the T-test. Multiple comparisons test (ANOVA) was used for comparing the different experiments. The significant difference was considered as $\mathrm{P}$-value $<0.05$.

\section{Results and Discussion}

\subsection{Synthesis of Ag/AgCl-NPs.}

Ethanol extract of $U$. fasciata was used as a reducing and inhibitory agent for the synthesis of $\mathrm{Ag} / \mathrm{AgCl}-\mathrm{NPs}$. During the reduction of $\mathrm{Ag}^{+}$, the UF-extract color changed from pale yellow to brown (Figure 1A). Therefore, the brown suspension appearance is considered a primary indicator to confirm the formation of $\mathrm{Ag} / \mathrm{AgCl}-\mathrm{NPs}$. Besides, Uv-vis spectroscopy showed a sharp peak at $413.5 \mathrm{~nm}$ due to a shift in surface plasmon resonance (SPR) caused by the reduction of $\mathrm{Ag}^{+}$to $\mathrm{Ag}^{0}$ (Figure 1B). In fact, with the reduction of silver ions and NPs' formation, a displacement occurs in the SPR due to the collective oscillations of conduction electrons in nanostructures [14]. As stated in the literature, the presence of SPR peak at 350$450 \mathrm{~nm}$ can be evidence of the successful formation of AgCl-NPs by UF-extract [15]. In agreement with Velgosová et al. (2016) report, our biosynthesized Ag/AgCl-NPs were synthesized with SPR shift from 410-415 nm at a $\mathrm{pH}$ value of 10 [16]. 


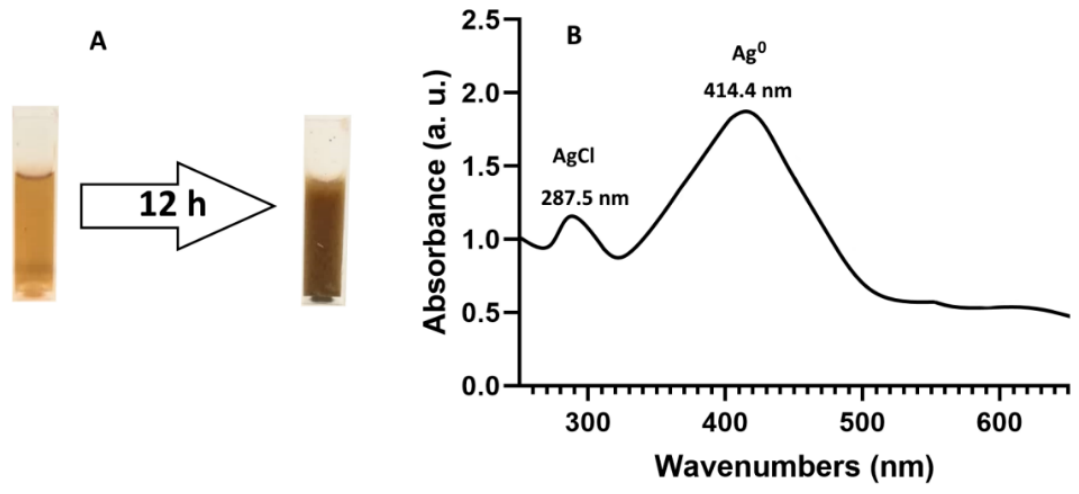

Figure 1. (A) color change of extract solution with the formation of Ag/AgCl-NPs. And (B) Uv-visible absorption of phyco-synthesized Ag/AgCl-NPs.

\subsection{Morphological characteristics of Ag/AgCl-NPs.}

SEM image was used for studying the shape and size of Ag/AgCl-NPs. As shown in Figure 2A, Ag/AgCl-NPs are almost spherical and few polygonal shapes with an average size of $50 \mathrm{~nm}$. Accordingly, the TEM micrograph revealed that the exact size of the NPs was in the range estimated by SEM. Also, the TEM image shows faint halos around the NPs attributed to the metabolites responsible for the capping and stability (Figure 2B). The EDX presented in Figure 4C elucidated elemental compositions involved in the formation of biogenic $\mathrm{Ag} / \mathrm{AgCl}-$ NPs. Two evidence peaks at $3 \mathrm{keV}$ and $2.6 \mathrm{keV}$ demonstrate SPR adsorption of silver and chloride, respectively. Therefore, the final crystal nature of $\mathrm{Ag} / \mathrm{AgCl}-\mathrm{NPs}$ is affected by the abundance of both of their constituents.
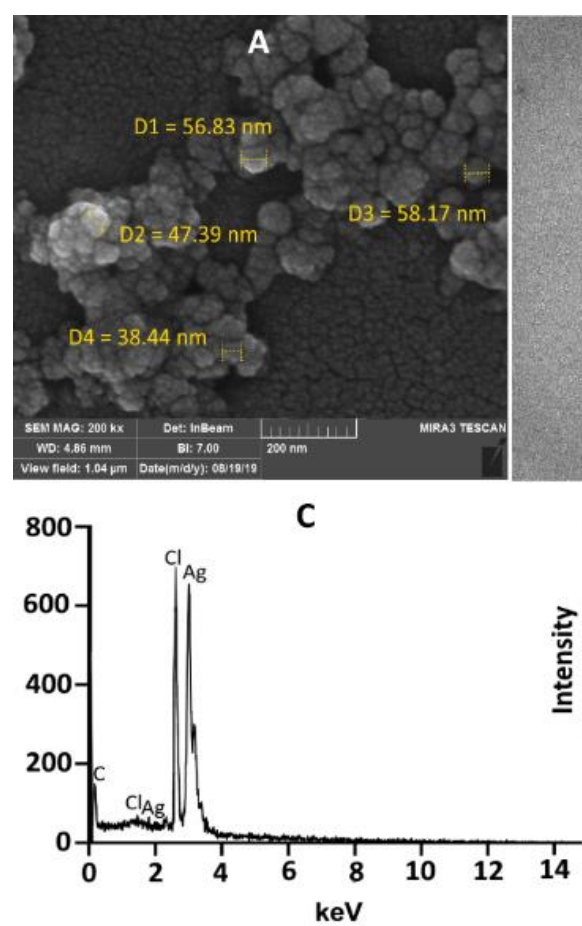

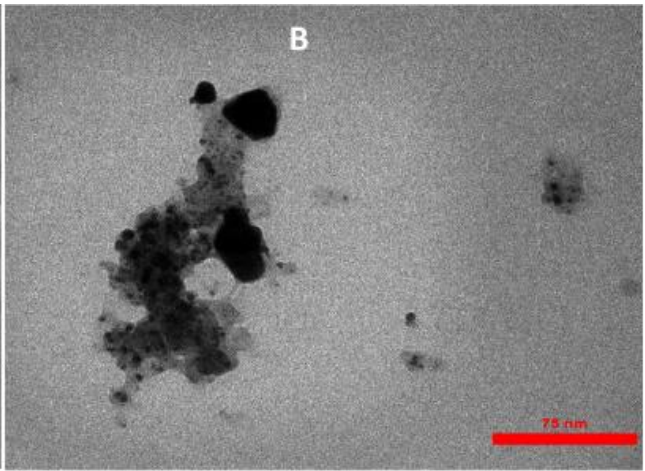

D

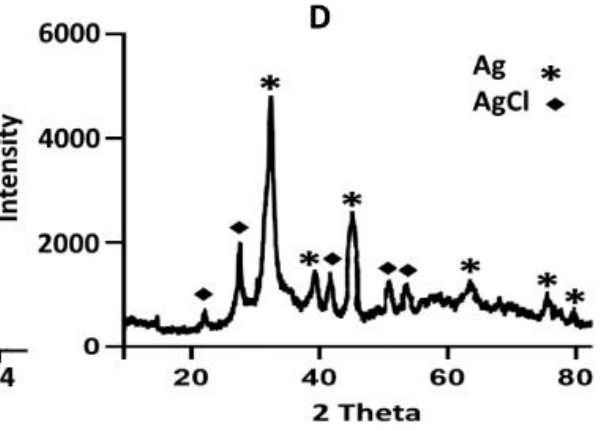

Figure 2. (A) SEM, (B) TEM images of Ag/AgCl-NPs synthesized by UF-extract, (C) and elemental analysis using EDX, and (D) Crystallography study by XRD.

\subsection{FTIR analysis of UF-extract and synthesized Ag/AgCl-NPs}

FTIR spectroscopy determined possible functional groups involved in reducing and capping metal elements. Indeed, chemical groups might be reduced during NPs synthesis or 
participate in non-covalent interaction for stabilizing them. As seen in Figure 3, peaks 3438.4 and $3438.1 \mathrm{~cm}^{-1}$ belong to the NPs formation process's hydroxyl groups. The decrease in the O$\mathrm{H}$ peak intensity indicated that some hydroxyl groups are involved in the NPs stability. A group of peaks observed in the range of 1500 to $2000 \mathrm{~cm}^{-1}$ is usually due to active carboxyl and carbonyl groups in biomolecules' structure. An important part of the peaks that stand out in the NPs synthesis process is a group of peaks in the region below $1000 \mathrm{~cm}^{-1}$ called fingerprints. Comparing Figures 3 and 4 shows that the fingerprint area peaks have disappeared in the spectrum of NPs, which is a strong reason for the involvement of these factor groups in the synthesis and stability of NPs.

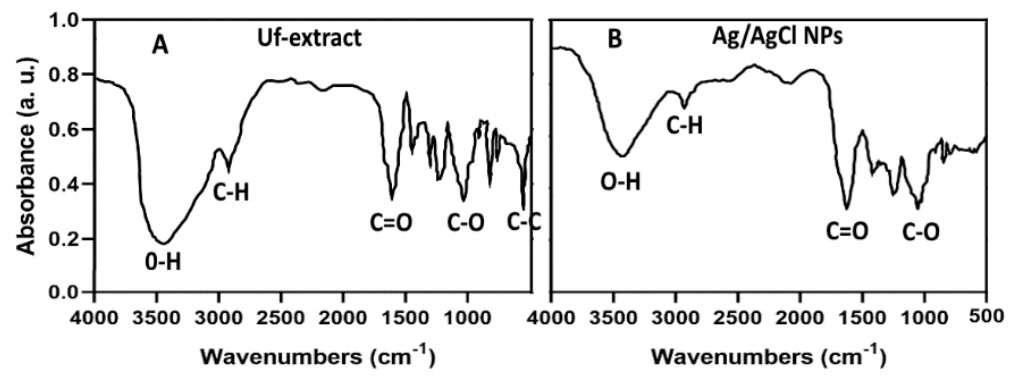

Figure 3. FTIR analyses of (A) UF-extract and (B) biosynthesized Ag/AgCl-NPs.

\subsection{Size distribution and surface charge.}

The zeta potential (ZP) and Dynamic light scattering were determined to study the surface charge and size distribution of $\mathrm{Ag} / \mathrm{AgCl}-\mathrm{NPs}$ in a colloidal state. Figure 4A presents the surface charge of the nanoparticles with a maximum $\mathrm{ZP}$ value of $-17.7 \mathrm{mV}$. In this study, the silver nanoparticles obtained represented relative stability. As the evidence suggests, nanoparticles with a surface charge of $\pm 30 \mathrm{mV}$ possess high aging stability. The size distribution of NPs in the colloidal solution was estimated to be $87.48 \mathrm{~nm}$ in the maximum state (Figure 4B). In fact, the particle size determined by the DLS technique refers to the hydrodynamic diameter of the particles in the aqueous phase. Therefore, the size of NPs calculated by DLS is expected to be larger than other measurements such as TEM and SEM [17]. The literature stated that biogenic NPs in more times are negatively charged in the aqueous solutions. Hence, they show high stability and biological activity in physiologic conditions. According to many studies, biologically active molecules play a critical role in the negative surface charge of NPs [18].
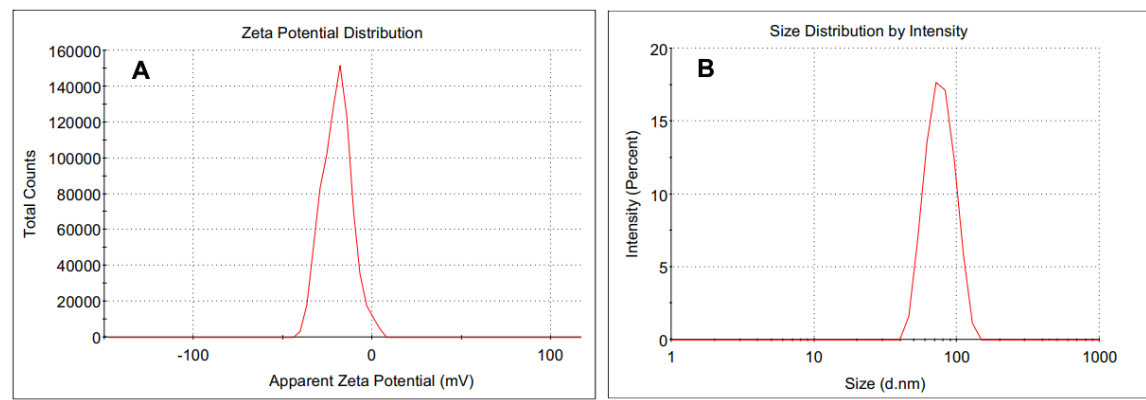

Figure 4. (A) Zeta potential distribution (ZP) within the surface of Ag/AgCl-NPs and (B) Particle size distributions (DLS) of $\mathrm{Ag} / \mathrm{AgCl}-\mathrm{NPs}$ in aqueous solution. 


\subsection{Antifungal activity of Ag/AgCl-NPs.}

The antifungal activity of $\mathrm{Ag} / \mathrm{AgCl}-\mathrm{NPs}$ against two different species of Candida was investigated. Figure 5 shows the well-diffusion test for varying concentrations of $\mathrm{Ag} / \mathrm{AgCl}-$ NPs. As can be seen, the growth inhibition zone increases as the concentration of NPs increases. Besides, the $\mathrm{IC}_{50}$ value was determined in terms of cell density in the MHB medium. This value was $12 \mu \mathrm{g} / \mathrm{ml}$ for $C$. albicans, while the $\mathrm{IC}_{50}$ concentration for $C$. glabrata was about $6 \mu \mathrm{g} / \mathrm{ml}$. Thus, $\mathrm{IC}_{50}$ results show that the antifungal effect of $\mathrm{Ag} / \mathrm{AgCl}-\mathrm{NPs}$ against $C$. glabrata is almost twice that of $C$. albicans. In contrast, the results of the well-diffusion test show the same antimicrobial activity against both strains. As Azam et al. (2012) described, the physicochemical properties of NPs had a direct impact on the rate of diffusion of them in wells that induced the growth inhibition zone around the fungal colonies [19]. Consequently, the equal diameter of the growth inhibition zone in both Candida species may be attributed to the limited diffusion of NPs in the agar. In general, several studies have confirmed the antifungal properties of AgCl-NPs. One of the main antifungal mechanisms of AgCl-NPs is to destroy the membrane's surface and disrupt its integrity [20]. On the other hand, the physicochemical properties of NPs play a significant role in their antifungal potency. As suggested by studies, smaller NPs have more penetration into the cells [21]. In the present study, the favorable properties of biosynthesized $\mathrm{Ag} / \mathrm{AgCl}-\mathrm{NPs}$ from UF-extract increased its antifungal activity.

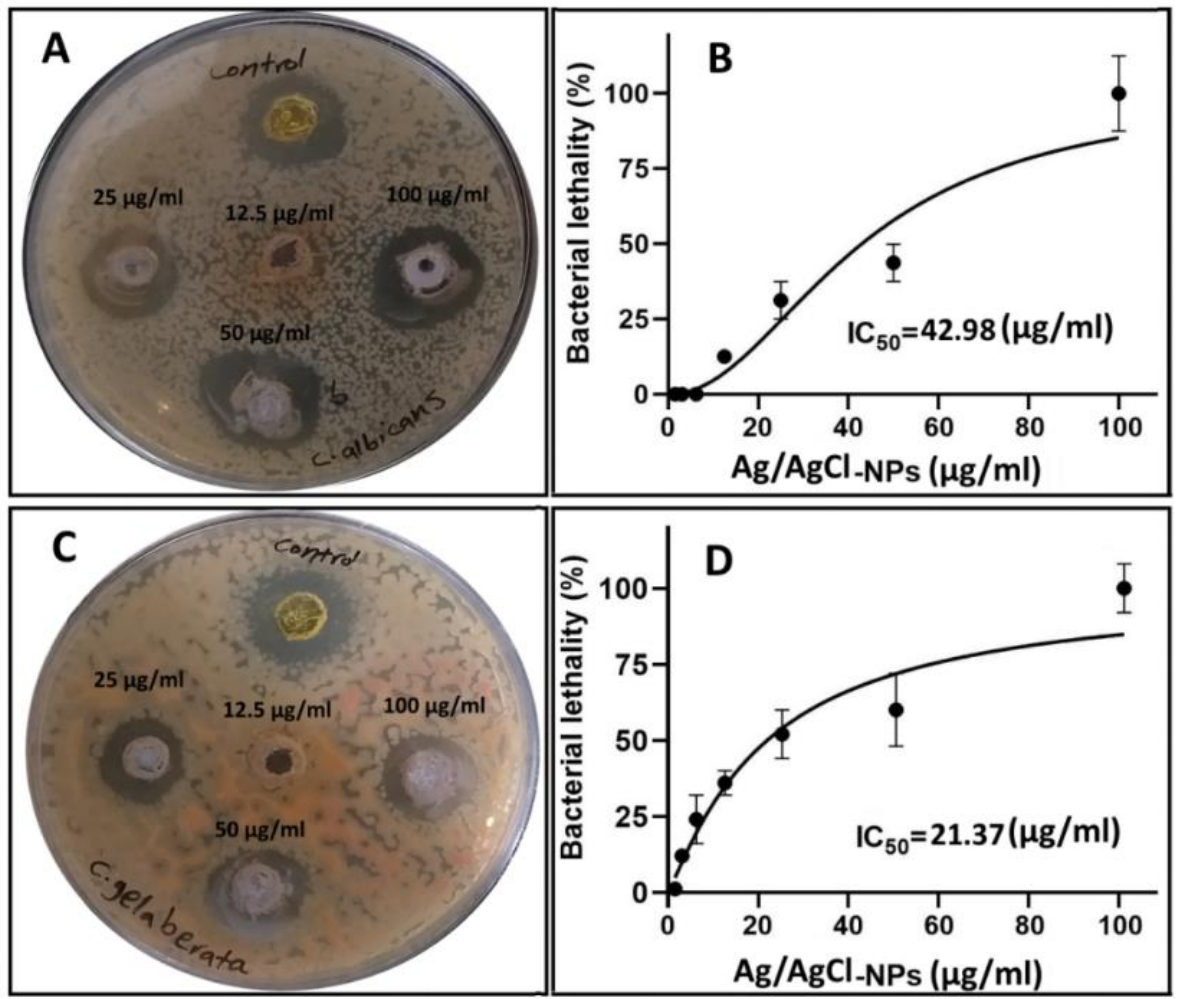

Figure 5. Antifungal activity assays of (A) and (C) show well-diffusion assay of C. albcans and C. glabrata and $\mathrm{IC}_{50}$ values of $\mathrm{Ag} / \mathrm{AgCl}-\mathrm{NPs}$ against $C$. albcans and C. glabrata.

\subsection{Antioxidant capacity of Ag/AgCl-NPs.}

The antioxidant activity of $\mathrm{Ag} / \mathrm{AgCl}-\mathrm{NPs}$ was determined by the DPPH scavenging as an indicating free radical neutralization capacity. As seen in Figure 6, DPPH inhibition by $\mathrm{Ag} / \mathrm{AgCl}-\mathrm{NPs}$ was a dose-dependent process. Antioxidant activity of Ag/AgCl-NPs, in which the highest value was $90 \%$ at a $50 \mu \mathrm{g} / \mathrm{ml}$ concentration. Additionally, the antioxidant activity 
of UF-extract, Ascorbic acid (AA), and BHA were 41.6, 100, and 81.09\%, respectively. According to the many reports, biosynthesized metallic NPs indicate remarkable antioxidant activity due to capping them with bioactive compounds. Therefore, capping agents could affect bioactivity and increase the reactivity of most metal NPs [22].

As started literature, although chemically synthesized NPs are found to be more potent than biologically based ones, biosynthesized NPs are demonstrated to be more appropriate for biomedical applications due to compatibility and eco-friendly features [23]. The biological properties of plant-based synthesized NPs can be attributed to various compounds such as polyphenols, flavonoids, proteins, and fatty acids in the algal extract, which have unique biological activity $[7,9,10]$.

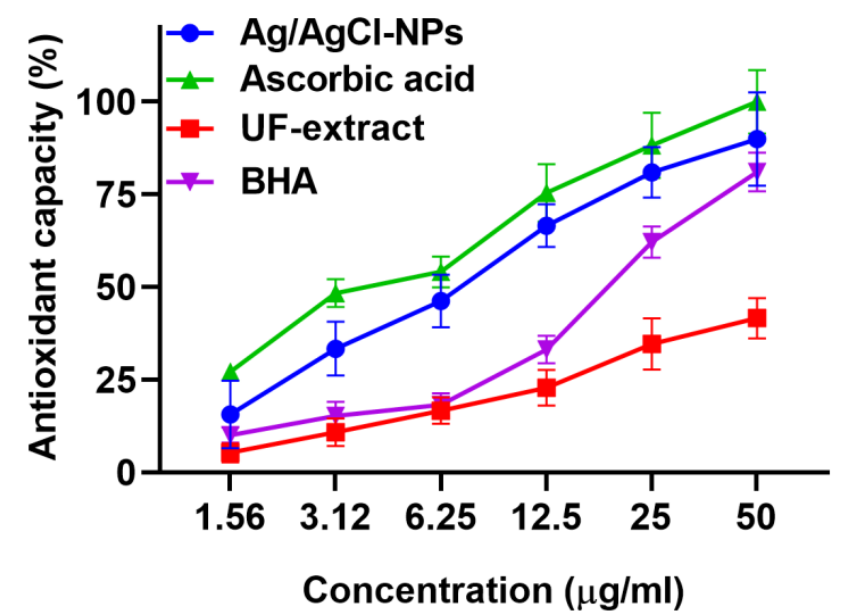

Figure 6. DPPH radical scavenging. Antioxidant potential of biosynthesized Ag/AgCl-NPs compared with ascorbic acid (AA), UF-extract, and butyl hydroxyanisole (BHA).

\subsection{Cytotoxicity assessment of Ag/AgCl-NPs.}

Cytotoxicity of $\mathrm{Ag} / \mathrm{AgCl}-\mathrm{NPs}$ and U-extract was examined using the MTT method. As seen in Figure 7, the toxicity effect of both treatments on the A549 cell line was dose-dependent so that with increasing the dose, cell viability was significantly decreased. Additionally, the $\mathrm{IC}_{50}$ value of $\mathrm{Ag} / \mathrm{AgCl}-\mathrm{NPs}$ and UF-extract were determined to be 32 and $7.38 \mu \mathrm{g} / \mathrm{ml}$, respectively. As anticipated, the potency of $\mathrm{Ag} / \mathrm{AgCl}-\mathrm{NPs}$ was higher than UF-extract. Although our results were consistent with the other reports, it could be demonstrated that greenbased $\mathrm{Ag} / \mathrm{AgCl}-\mathrm{NPs}$ exhibited a synergetic effect when was compared with other Ag-NPs synthesized via other methods $[24,25]$.
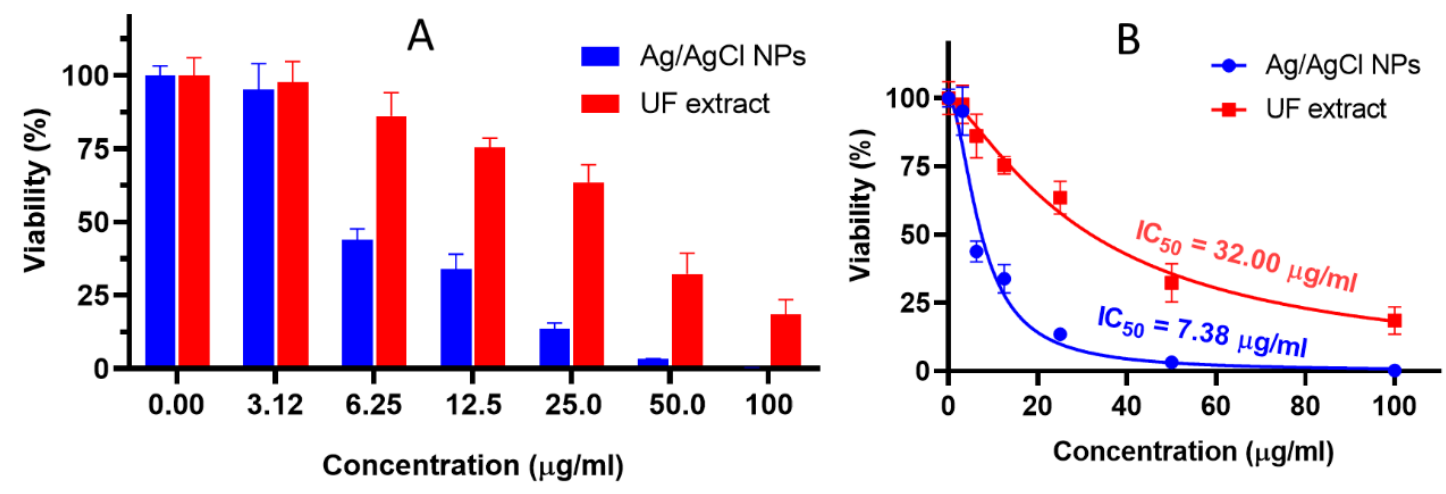

Figure 7. Viability (\%) of A549 cell line in the presence of different concentrations of Ag/AgCl-NPs and UFextract after $24 \mathrm{~h}$ incubation. 


\section{Conclusions}

The phyco-synthesized Ag/AgCl-NPs successfully achieved using ethanol extract of $U$. fasciata as a reducing and stabilizing agent. Since seaweed metabolites are high bioactive compounds, $\mathrm{Ag} / \mathrm{AgCl}$-capped biomolecules exhibited remarkable antifungal, antioxidant and anti-cancer activities. In this study, we conclude that UF-extract could be used for the biologically active NPs' synthesis due to the presence of various biological compounds with biocompatible, cost-effective, and easy-access features.

\section{Funding}

This work was financially supported by Lorestan University of Medical Sciences. The authors declare that no potential conflict of interest relevant to the present study.

\section{Acknowledgments}

This research has no acknowledgment.

\section{Conflicts of Interest}

The authors declare no conflict of interest.

\section{References}

1. Ahmad, S.; Munir, S.; Zeb, N.; Ullah, A.; Khan, B.; Ali, J.; Bilal, M.; Omer, M.; Alamzeb, M.; Salman, S. M.; Salman, S.M.; Ali, S. Green nanotechnology: A review on green synthesis of silver nanoparticles - An ecofriendly approach. International journal of nanomedicine 2019, 14, 5087-5107, https://doi.org/10.2147/IJN.S200254.

2. Khan, I.; Saeed, K.; Khan, I. Nanoparticles: Properties, applications and toxicities. Arabian Journal of Chemistry 2019, 12, 908-931, https://doi.org/10.1016/j.arabjc.2017.05.011.

3. Jamkhande, P.G.; Ghule, N.W.; Bamer, A.H.; Kalaskar, M.G. Metal nanoparticles synthesis: An overview on methods of preparation, advantages and disadvantages, and applications. Journal of Drug Delivery Science and Technology 2019, 53, https://doi.org/10.1016/j.jddst.2019.101174.

4. Jayabalan, J.; Mani, G.; Krishnan, N.; Pernabas, J.; Devadoss, J.M.; Jang, H.T. Green biogenic synthesis of zinc oxide nanoparticles using Pseudomonas putida culture and its In vitro antibacterial and anti-biofilm activity. Biocatalysis and Agricultural Biotechnology 2019, 21, https://doi.org/10.1016/j.bcab.2019.101327.

5. Reyes-Torres, M.A.; Mendoza-Mendoza, E.; Miranda-Hernández, Á.M.; Pérez-Díaz, M.A.; LópezCarrizales, M.; Peralta-Rodríguez, R.D.; Sánchez-Sánchez, R.; Martinez-Gutierrez, F. Synthesis of CuO and $\mathrm{ZnO}$ nanoparticles by a novel green route: Antimicrobial activity, cytotoxic effects and their synergism with ampicillin. Ceramics International 2019, 45, 24461-24468, https://doi.org/10.1016/j.ceramint.2019.08.171.

6. Muniyan, A.; Ravi, K.; Mohan, U.; Panchamoorthy, R. Characterization and in vitro antibacterial activity of saponin-conjugated silver nanoparticles against bacteria that cause burn wound infection. World Journal of Microbiology and Biotechnology 2017, 33, https://doi.org/10.1007/s11274-017-2309-3.

7. Sánchez-López, E.; Gomes, D.; Esteruelas, G.; Bonilla, L.; Lopez-Machado, A.L.; Galindo, R.; Cano, A.; Espina, M.; Ettcheto, M.; Camins, A.; Silva, A.M.; Durazzo, A.; Santini, A.; Garcia, M.L.; Souto, E.B. Metal-based nanoparticles as antimicrobial agents: An overview. Nanomaterials 2020, 10, https://doi.org/10.3390/nano10020292.

8. Medici, S.; Peana, M.; Nurchi, V.M.; Zoroddu, M.A. Medical uses of silver: history, myths, and scientific evidence. Journal of Medicinal Chemistry 2019, 62, 5923-5943, https://doi.org/10.1021/acs.jmedchem.8b01439.

9. Verma, P.; Maheshwari, S.K. Applications of Silver nanoparticles in diverse sectors. International Journal of Nano Dimension 2019, 10, 18-36.

10. Hussain, M.; Raja, N.I.; Iqbal, M.; Aslam, S. Applications of plant flavonoids in the green synthesis of colloidal silver nanoparticles and impacts on human health. Iranian Journal of Science Technology, Transactions A: Science 2019, 43, 1381-1392, https://doi.org/10.1007/s40995-017-0431-6.

11. Roy, S. A Review: Green Synthesis of Nanoparticles from Seaweeds and Its some Applications. Austin Journal of Nanomedicine and Nanotechnology 2019, 7. 
12. de Aragao, A.P.; de Oliveira, T.M.; Quelemes, P.V.; Perfeito, M.L.G.; Araujo, M.C.; Santiago, J.d.A.S.; Cardoso, V.S.; Quaresma, P.; de Almeida, J.R.d.S.; da Silva, D.A. Green synthesis of silver nanoparticles using the seaweed Gracilaria birdiae and their antibacterial activity. Arabian Journal of Chemistry 2019, 12, 4182-4188, https://doi.org/10.1016/j.arabjc.2016.04.014.

13. Jeevitha, M.; Rajeshkumar, S. Antimicrobial Activity of Silver Nanoparticles Synthesized Using Marine Brown Seaweed Spatoglossum Asperum Against Oral Pathogens. Indian Journal of Public Health Research and Development 2019, 10.

14. Amin, M.; Anwar, F.; Janjua, M.R.; Iqbal, M.A.; Rashid, U. Green synthesis of silver nanoparticles through reduction with Solanum xanthocarpum L. berry extract: characterization, antimicrobial and urease inhibitory activities against Helicobacter pylori. Int $J$ Mol Sci 2012, 13, 9923-9941, https://doi.org/10.3390/ijms13089923.

15. Thangaraj, V.; Mahmud, S.; Li, W.; Yang, F.; Liu, H. Greenly synthesised silver-alginate nanocomposites for degrading dyes and bacteria. IET Nanobiotechnology 2018, 12, 47-51, https://doi.org/10.1049/ietnbt.2017.0074.

16. Velgosová, O.; Mražíková, A.; Marcinčáková, R. Influence of pH on green synthesis of Ag nanoparticles. Materials Letters 2016, 180, 336-339, https://doi.org/10.1016/j.matlet.2016.04.045.

17. Vogel, R.; Pal, A.K.; Jambhrunkar, S.; Patel, P.; Thakur, S.S.; Reátegui, E.; Parekh, H.S.; Saá, P. Stassinopoulos A, Broom MF. High-resolution single particle zeta potential characterisation of biological nanoparticles using tunable resistive pulse sensing. Scientific Reports 2017, 7, 1-3, https://doi.org/10.1038/s41598-017-14981-x

18. Mirzaei, S.Z.; Ahmadi Somaghian, S.; Lashgarian, H.E.; Karkhane, M.; Cheraghipour, K.; Marzban, A. Phyco-fabrication of bimetallic nanoparticles (zinc-selenium) using aqueous extract of Gracilaria corticata and its biological activity potentials. Ceramics International 2020, 47, 5580-5586, https://doi.org/10.1016/j.ceramint.2020.10.142.

19. Azam, A.; Ahmed, A.S.; Oves, M.; Khan, M.S.; Memic, A. Size-dependent antimicrobial properties of CuO nanoparticles against Gram-positive and -negative bacterial strains. International journal of nanomedicine 2012, 7, 3527-3535, https://doi.org/10.2147/IJN.S29020.

20. Bocate, K.P.; Reis, G.F.; de Souza, P.C.; Oliveira Junior, A.G.; Durán, N.; Nakazato, G.; Furlaneto, M.C.; de Almeida, R.S.; Panagio, L.A. Antifungal activity of silver nanoparticles and simvastatin against toxigenic species of Aspergillus. International Journal of Food Microbiology 2019, 291, 79-86, https://doi.org/10.1016/j.ijfoodmicro.2018.11.012.

21. del Pilar Rodríguez-Torres, M.; Acosta-Torres, L.S.; Díaz-Torres, L.A.; Padrón, G.H.; García-Contreras, R.; Millán-Chiu, B.E. Artemisia absinthium-based silver nanoparticles antifungal evaluation against three Candida species. Materials Research Express 2019, 6, https://doi.org/10.1088/2053-1591/ab1fba.

22. Handago, D.T.; Zereffa, E.A.; Gonfa, B.A. Effects of Azadirachta indica leaf extract, capping agents, on the synthesis of pure and $\mathrm{Cu}$ doped $\mathrm{ZnO}$-nanoparticles: a green approach and microbial activity. Open Chemistry 2019, 17, 246-253, https://doi.org/10.1515/chem-2019-0018.

23. Ahmed, M.J.; Murtaza, G.; Rashid, F.; Iqbal, J. Eco-friendly green synthesis of silver nanoparticles and their potential applications as antioxidant and anti-cancer agents. Drug Development Industrial Pharmacy 2019, 45, 1682-1694, https://doi.org/10.1080/03639045.2019.1656224.

24. Alishah, H.; Pourseyedi, S.; Mahani, S.E.; Ebrahimipour, S.Y. Extract-mediated synthesis of Ag@ AgCl nanoparticles using Conium maculatum seeds: characterization, antibacterial activity and cytotoxicity effect against MCF-7 cell line. RSC advances 2016, 6, 73197-73202, https://doi.org/10.1039/C6RA16127H.

25. Kabir, S. R.; Dai, Z.; Nurujjaman, M.; Cui, X.; Asaduzzaman, A.; Sun, B.; Zhang, X.; Dai, H.; Zhao, X. Biogenic silver/silver chloride nanoparticles inhibit human glioblastoma stem cells growth in vitro and Ehrlich ascites carcinoma cell growth in vivo. Journal of Cellular and Molecular Medicine 2020, 24, 1322313234, https://doi.org/10.1111/jcmm.15934. 